\title{
Variations in Intralipid Tolerance in Newborn Infants
}

\author{
ELIZABETH A. GRIFFIN, ${ }^{(30)}$ M. HEATHER BRYAN, ${ }^{(31)}$ AND AUBIE ANGEL \\ The Research Institute of the Hospital for Sick Children and The Division of Endocrinology and Metabolism, Toronto \\ General Hospital, University of Toronto, Toronto, Ontario, Canada
}

\begin{abstract}
Summary
Intravenous Intralipid tolerance tests (IVLTT) were done in $\mathbf{2 6}$ newborn infants of 26-40 wk gestational ages. The clearance constants $\left(k_{2}\right)$ ranged from $1.2-12.7(\% / \mathrm{min})$ after bolus injections given within $4.5 \mathrm{~h}(n=12)$ or daily $(n=13)$. Significant variation (17-31\%) occurred, similar to adults, and was unrelated to the time or dose given. Eleven infants received continuous Intralipid infusions for 10-24 h at a rate calculated to maintain a plasma Intralipid plateau concentration of $100 \mathrm{mg} / \mathrm{dl}$. Nine infants did not exceed this optimal plasma level, although four could have tolerated more Intralipid. Two infants exceeded the ideal plasma concentration (>100 mg/dl). All infants achieved and maintained plateaus within $5 \mathrm{~h}$. Neither day-to-day variations nor the bolus dose used to establish clearance characteristics, accounted for the discrepancies in plateaus achieved. These studies identify some limitations of the IVLTT as a predictor of Intralipid utilization during continuous infusion, and the need for early monitoring of plasma Intralipid concentrations to optimize the therapeutic dose given to newborn infants.
\end{abstract}

Abbreviations

IVLTT, intravenous Intralipid tolerance

Lp-X, Lipoprotein-X

TPN, total parenteral nutrition

The advantages of intravenous fat emulsion are the calories that it provides, and the supply of essential fatty acids necessary for normal cellular metabolism, growth, and development. Intralipid, the parenteral lipid emulsion commonly used has been recommended at doses of up to $4 \mathrm{~g} \cdot \mathrm{kg}^{-1} \cdot \mathrm{day}^{-1}$ in infants $(25,29)$ although some tolerate higher intakes (8). Hallberg (17) first delineated the plasma clearance characteristics of bolus injections of Intralipid in adult man showing that below a certain plasma lipid concentration, clearance was exponential, obeying first order kinetics. Gustafson et al. (15) studying newborn infants, demonstrated that the plasma clearance of bolus injections was similar to that of adults. But lower postheparin lipoprotein lipase activity has been noted in premature infants $(5,25)$ compared to term babies (25), which may explain Shennan's observations (23) that after a single injection, premature infants cleared Intralipid from plasma at approximately half the rate of mature newborns. Furthermore, we have noted the continuous infusion of Intralipid in adults (13) and the neonate (12) is associated with the appearance of Lipoprotein-X ( $\mathrm{Lp}-\mathrm{X})$ in plasma at levels proportional to the amount and duration of the infusion. In addition, many recent reports of its possible disadvantages such as hypoxemia (21), pulmonary fat accumulation in sick neonates (19) and reduced defences against bacterial infection in animal and adult neutrophil studies $(4,6,7)$ prompted us to report the present study, which was designed to rationalize the safe delivery of Intralipid by continuous infusion to newborn infants on parenteral nutrition as their sole course of nutrients.

The reproducibility and the predictive value of the intravenous
Intralipid tolerance test (IVLTT) in the calculation of an infusion rate to maintain the plasma Intralipid level at a predetermined concentration was assessed. As Intralipid clearance at physiologic triglyceride concentrations is considered to be exponential (17, $23)$, the formula of the plateau principle $(10,11)$ from pharmacokinetics was applied to predict individual infusion rates. The plateau principal assumes that the plasma Intralipid concentration is achieved when the rate of Intralipid infusion equals the rate of Intralipid removal from the plasma compartment.

\section{PATIENTS AND METHODS}

In order to assess the variability of the response of newborn infants to bolus injections of 10\% Intralipid, 26 infants (seven full term and 19 premature) were studied. All were appropriate for gestational age at birth and had bilirubin concentrations less than $5 \mathrm{mg} / \mathrm{dl}$ when studied at postnatal ages of 3-20 days.

In 12 infants, three consecutive IVLTTs were carried out over $4.5 \mathrm{~h}$ : six after a bolus of $100 \mathrm{mg} / \mathrm{kg}$ Intralipid and six after a 200 $\mathrm{mg} / \mathrm{kg}$ bolus dose (Table 1). Before commencing the protocol (Table 1), seven patients had been formula fed, whereas five were unable to tolerate oral feeding because of congenital gastrointestinal anomalies or necrotizing enterocolitis. All 12 patients were given basal calories as dextrose and water intravenously (40-50 $\mathrm{kcal} \cdot \mathrm{kg}^{-1} \cdot \mathrm{day}^{-1}$ ) for $4 \mathrm{~h}$ before and during the IVLTTs.

An additional 12 infants received bolus injections of Intralipid $(200 \mathrm{mg} / \mathrm{kg}$ ) on two consecutive days before continuous Intralipid infusions (Table 2). Four of these same infants, plus another, had IVLTTs at bolus injections of $200 \mathrm{mg} / \mathrm{kg}$ preceding and $1-2 \mathrm{~h}$ after 20-24 h of continuous Intralipid infusions (Table 2). All these infants required total parenteral nutrition because of congenital anomalies in nine, necrotizing enterocolitis in three, and intolerance to feeds in two. They received constant infusions of intravenous glucose and casein hydrolysate for at least $4 \mathrm{~h}$ before their first tolerance test and continuously during the studies. Their individual non-fat calorie intakes ranged from $28-76 \mathrm{kcal} \cdot \mathrm{kg}^{-1}$. day $^{-1}$.

Intralipid plasma clearance was studied after a bolus injection of Intralipid 10\% (100 or $200 \mathrm{mg} / \mathrm{kg}$ ) given by scalp vein needle over $1 \mathrm{~min}$, and the clearance measured serially at $1,2,5,10,15$, $20,30,40$, and $60 \mathrm{~min}$, using a Thorp nephelometer to measure plasma turbidity as described by Carlson and Rossner (3) and later modified by Shennan et al. (23) for small volumes $(50 \mu \mathrm{l})$ of capillary heel blood. This method measures the large light scattering particles in the plasma and does not include small endogenous, e.g., very low density lipoprotein, low density lipoprotein, or high density lipoprotein particles (22). No adverse effect to the bolus injections was observed in any baby.

A group of 11 infants (No. 15 to 23 and 25, Table 2, and one other) received continuous Intralipid infusions at doses calculated from IVLTTs done on the same day the continuous Intralipid infusions commenced. Continuous infusion rates were then calculated using the clearance constant derived from the IVLTT performed on the same day by applying the equation of the 
Table 1. The reproducibility of three consecutive intravenous Intralipid tolerance tests in 12 newborn infants. Consecutive Intralipid tolerance tests over a 4.5-h period after a bolus injection at two doses ${ }^{1}$

\begin{tabular}{|c|c|c|c|c|c|}
\hline \multirow[b]{2}{*}{ Baby } & \multirow{2}{*}{$\begin{array}{c}\text { Gestation } \\
\text { (wk) }\end{array}$} & \multirow{2}{*}{$\begin{array}{c}\text { Age } \\
\text { (days) }\end{array}$} & \multicolumn{3}{|c|}{$\mathbf{k}_{2}(\%$ Intralipid clearance $/ \mathrm{min}) \pm$ S.E.M. } \\
\hline & & & Test 1 & Test 2 & Test 3 \\
\hline \multicolumn{6}{|c|}{ Intralipid bolus dose, $100 \mathrm{mg} / \mathrm{kg}$} \\
\hline 1 & 27 & 11 & $1.72 \pm 0.05$ & $2.00 \pm 0.16$ & $2.84 \pm 0.31^{2}$ \\
\hline 2 & 28 & 8 & $2.73 \pm 0.20$ & $3.35 \pm 0.12$ & $2.77 \pm 0.13$ \\
\hline 3 & 30 & 4 & $9.73 \pm 0.77$ & $12.74 \pm 1.50$ & $11.38 \pm 1.10$ \\
\hline 4 & 34 & 5 & $6.07 \pm 0.22$ & $7.24 \pm 1.50^{2}$ & $5.58 \pm 1.10$ \\
\hline 5 & 35 & 10 & $4.97 \pm 0.47^{2}$ & $6.85 \pm 0.60$ & $7.16 \pm 0.33$ \\
\hline 6 & 36 & 6 & $5.73 \pm 0.65$ & $6.92 \pm 0.55$ & $6.65 \pm 0.60$ \\
\hline \multicolumn{6}{|c|}{ Intralipid bolus dose, $200 \mathrm{mg} / \mathrm{kg}$} \\
\hline 7 & 29 & 5 & $3.80 \pm 0.22$ & $2.56 \pm 0.12^{2}$ & $3.24 \pm 0.20$ \\
\hline 8 & 30 & 3 & $4.32 \pm 0.29$ & $4.59 \pm 0.34$ & $4.34 \pm 0.22$ \\
\hline 9 & 32 & 5 & $8.57 \pm 0.57^{2}$ & $5.97 \pm 0.66$ & $4.80 \pm 1.80$ \\
\hline 10 & 32 & 12 & $4.35 \pm 0.34$ & $4.80 \pm 0.38$ & $4.79 \pm 0.57$ \\
\hline 11 & 40 & 7 & $4.52 \pm 0.56$ & $6.31 \pm 0.29$ & $6.67 \pm 0.32$ \\
\hline 12 & 40 & 8 & $7.10 \pm 0.53$ & $5.54 \pm 0.60$ & $6.33 \pm 0.26$ \\
\hline
\end{tabular}

${ }^{1}$ The dose of Intralipid did not affect the reproducibility of the intravenous Intralipid tolerance test in each patient and could not account for the degree of variation within each group.

${ }^{2} \mathrm{k}_{2}$ significantly different from the remaining two $(P<0.05)$.

Table 2. The reproducibility of intravenous Intralipid tolerance tests in newborn infants studied on two consecutive days ( $n=12)$, and before and after continuous Intralipid infusions $(n=5){ }^{1}$

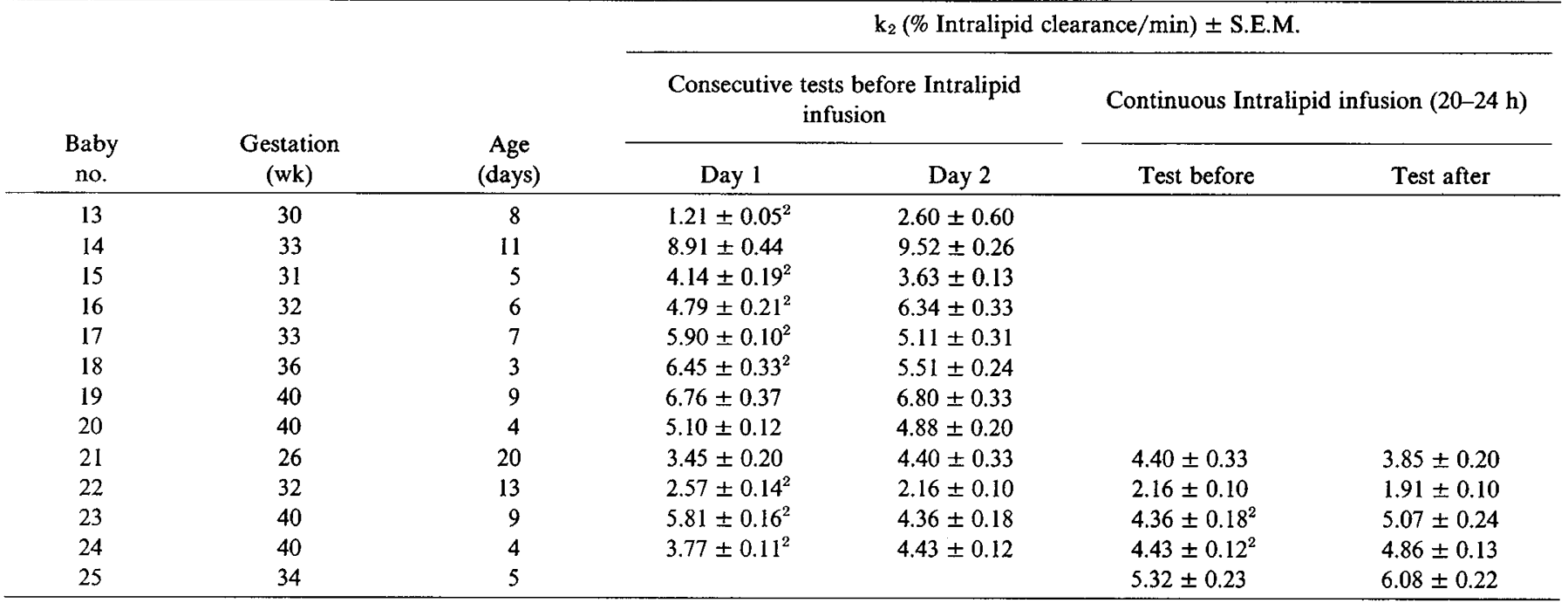

${ }^{1}$ Neither the timing of the intravenous Intralipid tolerance test before continuous infusion, nor 20-24 h of continuous infusion had any systematic effect on the reproducibility.

${ }^{2} \mathrm{k}_{2}$ significantly different from the other $(P<0.05)$.

plateau principle $(10,11)$ as follows: Intralipid infusion rate $(\mathrm{mg} /$ h) $=60 \mathrm{k} . V \mathrm{~d} . \mathrm{C}$, where $\mathrm{k}$, fractional elimination constant per min; Vd, volume of distribution ( $\mathrm{ml}$ ); and $\mathrm{C}$, target Intralipid plasma concentration $(\mathrm{mg} / \mathrm{ml})$. The volume of distribution was estimated by extrapolating the slope of the disappearance curve to time zero and dividing the intercept concentration by the injection dose in mg. A target plasma Intralipid concentration (C) of $100 \mathrm{mg} / \mathrm{dl}$ was arbitrarily set, as Forget et al. (8) has shown that concentrations above this were associated with hyperlipoproteinemia. In practice, the actual target concentrations ranged from $91-104 \mathrm{mg} /$ dl. We have confirmed, in a separate group of 10 formula fed infants receiving $5-10 \mathrm{~g} \cdot \mathrm{kg}^{-1} \cdot \mathrm{day}^{-1}$ fat of similar age $(11 \pm 2$ days, mean \pm S.E.), and gestation ( $34 \pm 1.7$ wk, mean \pm S.E.), that measured plasma turbidity did not exceed $90 \mathrm{mg} / \mathrm{dl}(56 \pm 6$, mean \pm S.E.).

The infants were infused with Intralipid at the calculated rate through a separate scalp vein needle, using a Sage syringe pump (Model No. 255-2) to maintain a constant rate of infusion. The time (t) to reach $95 \%$ of the target concentration was predicted for each infant using the plateau principle equation (10) where $t=$ $3 / \mathrm{k}$. It ranged from $42-139 \mathrm{~min}$ for the group.

Statistical methods. The Intralipid clearance constant (k) was computed using a Hewlett Packard program, which computes the least squares fit for pairs of data points for an exponential equation of the form: $y=a_{0} e^{-k t}$, where $y$, Intralipid concentration $(\mathrm{mg} / \mathrm{dl})$, $\mathrm{a}_{\mathrm{o}}$, initial Intralipid concentration $(\mathrm{mg} / \mathrm{dl}), \mathrm{k}$, slope (clearance/ $\min$ ); and $\mathrm{t}$, time (min).

The standard error of $k$ was calculated and reflects the variance of this slope. Comparison of the clearance constants $(k)$ was made by analysis of covariance. Where there were three tolerance tests for each infant and when the $\mathbf{k}$ difference was significant, Duncan's multiple range test was employed (26). This generates a significance matrix at 0.05 significance level for each infant. Overall group analysis was also performed on those infants from both groups in whom there were three tolerance tests. The S.E. of the expected plateau concentration was calculated (18). The ex- 


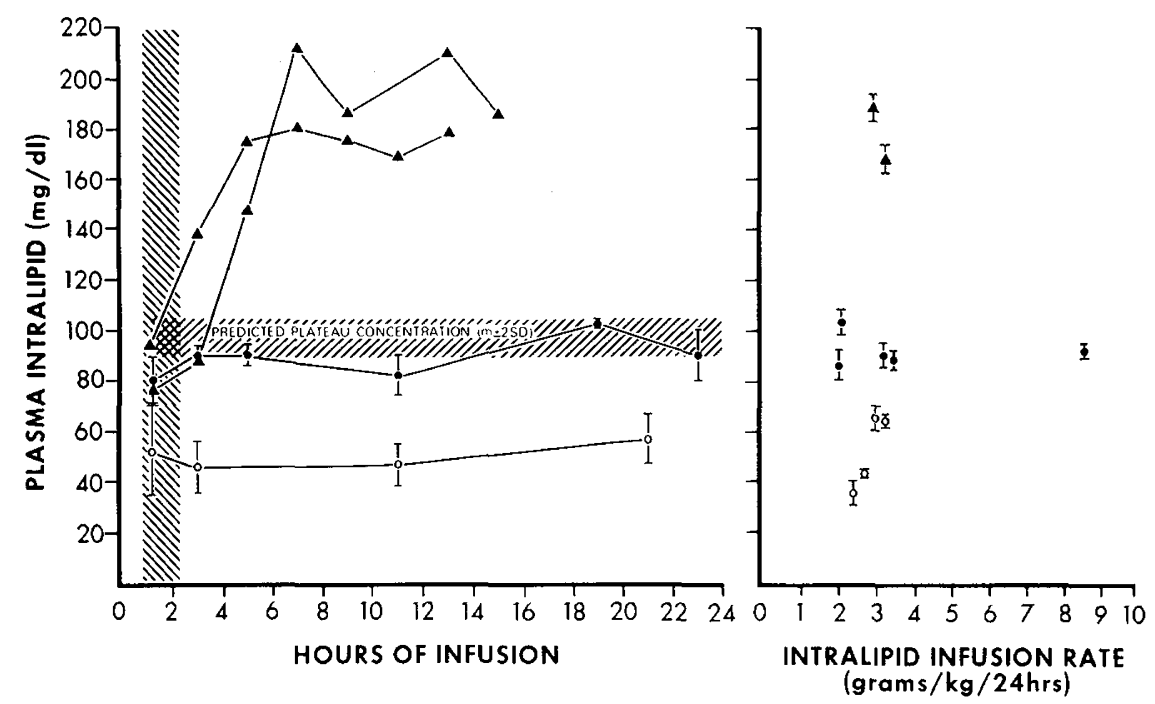

Fig. 1. Plasma Intralipid levels during continuous infusion in 11 newborn infants Left hand panel, Intralipid concentrations are plotted for a group of five infants who maintained the predicted plateau concentration, mean \pm S.D. (O); and for a group of four infants who failed to achieve it $(O)$. Two infants who exceeded their predicted plateaus are plotted individually (A). The vertically shaded area is the time expected to achieve $95 \%$ of the predicted plateau concentration, presented by the horizontal shaded area. Right hand panel, the individual Intralipid infusion rate is related to the plasma Intralipid concentrations (mean \pm S.D.) for each infant.

pected and calculated plateaus were compared using the standard normal variable (27).

\section{RESULTS}

The clearance constants obtained from the bolus injections after first order kinetics were similar to Hallberg's findings in adults (17) and Shennan's in newborns (23). Analysis of the Intralipid clearance constants $(\mathbf{k})$, expressed as \% clearance per min $\left(\mathrm{k}_{2}\right)$, of the individual infants revealed a wide variation in the response to the bolus injections. Of the infants who had three consecutive tolerance tests within a $4.5 \mathrm{~h}$ period (Table 1), one tolerance test differed significantly $(P<0.05)$ from the other two tests in five of the 12 infants studied. The injection dose $(100$ or $200 \mathrm{mg} / \mathrm{kg}$ ) had no influence on the variability of the clearance constants, for significant differences occurred in three infants receiving $100 \mathrm{mg} /$ $\mathrm{kg}$ and in two who were given $200 \mathrm{mg} / \mathrm{kg}$. Eight of the 12 infants (Table 2) studied on two consecutive days showed a significant day-to-day difference $(P<0.05)$ in clearance. Tolerance tests done before and after a $20-24 \mathrm{~h}$ continuous infusion of Intralipid (Table 2) also showed a significant difference in two of five infants.

The plateaus obtained in the infants infused with Intralipid at a rate calculated from the same day IVLTT are shown in Figure 1. Seven of the 11 infants achieved $95 \%$ of the target concentration within the predicted time (42-139 mins). All the infants maintained their plateaus throughout the infusion, although two achieved higher plateaus and four were lower than expected. The calculated Intralipid dose ranged from $2-3.8 \mathrm{~g} \cdot \mathrm{kg}^{-1} \cdot \mathrm{day}^{-1}$ with the exception of one infant who received and tolerated $8.6 \mathrm{~g} \cdot \mathrm{kg}^{-1}$. day $^{-1}$ (Figure right); thus, in 10 of 11 instances, the dose was within current recommended usage (29). Plasma volumes of distribution of Intralipid in the infants are given in Table 3 (mean \pm S.E.). Day-to-day Intralipid volumes of distribution did not alter significantly and they were similar to calculated plasma volumes derived from individual hematocrits and a blood volume of $110 \mathrm{ml} / \mathrm{kg} \mathrm{(24)} \mathrm{(Table} \mathrm{3).}$

\section{DISCUSSION}

The present study was undertaken to rationalize intravenous lipid therapy in individual newborn infants by studying the plasma clearance characteristics after a bolus injection of Intralipid and then applying the derived clearance constant $(k)$ and lipid volume
Table 3. Plasma volume (Vpl) [calculated from body weight (g) and hematocrit] compared with the Intralipid volume of distribution (Vd) (mean \pm S.E.M.) calculated from the intravenous Intralipid tolerance test

\begin{tabular}{lccc}
\hline & & & After \\
& Day 1 & Day 2 & infusion \\
\hline & $n=12$ & $n=14$ & $n=5$ \\
Vpl (ml) & $106 \pm 15$ & $110 \pm 12$ & $123 \pm 28$ \\
Vd (ml) & $109 \pm 19$ & $100 \pm 16$ & $103 \pm 20$ \\
$\mathbf{r}^{1}$ & 0.75 & 0.87 & 0.99 \\
\hline
\end{tabular}

${ }^{1}$ Correlation coefficient, $P<0.01$.

of distribution to the well established formula of the pharmacokinetic plateau principle $(10,11)$. The results show that during the infusion of Intralipid, plateaus were achieved and maintained in all the infants (Figure 1). In two infants, however, the Intralipid plasma levels rose significantly above that predicted into ranges considered at risk for hyperlipidemia (8), and accounted for the early termination of the infusion. The intolerance was apparent within $5 \mathrm{~h}$ of commencing the infusion. In another four infants, the levels were significantly less than predicted. These differences reflect the limitation of the IVLTT as a predictor of Intralipid utilization during continuous infusion in infants requiring total parenteral nutrition. The variation in clearance characteristics from repeated IVLTTs did not explain the discrepancies between predicted and observed plateau concentrations.

Carlson and Rossner (3) studied the variation of the IVLTT clearance characteristics in adults by examining the ratio of the constants of one test to another. We found ratios of $0.79-1.07$ (Table 4) in babies, which is similar to those noted in adults (3). Because the method of expressing variability as a ratio of clearance constants may obscure the true inter-test variations, we calculated the $\%$ variation in infants in whom three IVLTTs were done and the maximum variation between tests ranged from $17-27 \%$ (Table 4).

The mechanisms responsible for the varied responses in infants who failed to achieve or who exceeded plasma target Intralipid concentrations are not evident from this study. The possibility however, that these reflect variations in adipose and muscle tissue lipoprotein lipase activities warrents direct evaluation as this enzyme is the rate limiting step in the physiologic clearance of 
Table 4. Reproducibility of Intralipid clearance during intravenous Intralipid tolerance tests in infants

\begin{tabular}{lllcr}
\multicolumn{1}{c}{$\begin{array}{c}\text { Intralipid dose } \\
\left(\mathrm{mg} \cdot \mathrm{kg}^{-1}\right)\end{array}$} & $n^{1}$ & $\begin{array}{c}\text { Time between } \\
\text { IVLTTs }\end{array}$ & $\begin{array}{c}\text { Ratio } \\
\text { Mean } \pm \text { S.E.M. }\end{array}$ & $\begin{array}{c}\% \text { Variation } \\
\text { Mean } \pm \text { S.E.M. }\end{array}$ \\
\hline 100 & 4 & $30 \mathrm{~min}$ & $0.79 \pm 0.03$ & $27 \pm 4$ \\
200 & 5 & $30 \mathrm{~min}$ & $1.06 \pm 0.13$ & $26 \pm 8$ \\
200 & 6 & $24 \mathrm{~h}$ & $1.07 \pm 0.08$ & $17 \pm 5$ \\
Continuous infusion dose & & & & $31 \pm 9^{4}$ \\
$2-8.6 \mathrm{~g} \cdot \mathrm{kg} \cdot^{-1} \cdot$ day $^{-1}$ & 6 & & & \\
\hline
\end{tabular}

${ }^{1}$ Patients with $\mathrm{k}_{2}>4.0$ were selected to allow comparisons with the data of Carlson ${ }^{2}$ (3).

$2 \frac{k_{2}, 1 \text { st IVLTT }}{k_{2}, 2 \text { IVLTT }}$

$\mathrm{k}_{2}$, 2nd IVLTT

${ }_{3}$ highest $\mathrm{k}_{2}$-lowest $\mathrm{k}_{2} \times 100$

lowest $\mathbf{k}_{2}$

${ }^{4}$ Calculated from the plateau principle formula, see "Materials and Methods."

triglyceride particles. In an attempt to explain the findings in infants who did not achieve their target concentrations, it is possible that Intralipid infusions initiated an enhancement of clearance during the initial h of infusion, as Forget (8) has shown that Intralipid utilization during long term total parenteral nutrition improves. The two infants who exceeded the target plateau concentrations and became hypertriglyceridemic, differed from the others in that they were below the 3rd percentile for weight (28) at the time of study (though appropriate weight at time of birth), thus resembling small for gestational age $(1,16)$ and marasmic infants (14), who are known to have a delayed lipid clearance.

On the basis of the present study, most infants infused with Intralipid at $2-4 \mathrm{mg} \cdot \mathrm{kg}^{-1} \cdot \mathrm{day}^{-1}$ clear it adequately, but none the less two infants did not, and individual tolerance remains difficult to predict. As impaired clearance was evident in the two cases within $5 \mathrm{~h}$ of infusion (Figure 1), it is suggested that plasma Intralipid levels be monitored by that time so that the infant can be re-evaluated and adjustment in infusion rates made. Early plasma monitoring may avoid the hazards of Intralipid excess in susceptible infants $(2,4,6,7,19,21)$. It will not however prevent the hyperphospholipidemia and hypercholesterolemia $(9,12,13)$ and the accumulation of $\mathrm{Lp}-\mathrm{X}(12,13,20)$ associated with Intralipid therapy in adults and newborn infants.

\section{REFERENCES AND NOTES}

1. Andrew, G., Chan, G., and Schiff, D.: Lipid metabolism in the neonate. I. The effects of Intralipid infusion on plasma triglyceride and free fatty acid concentration in the neonate. J. Pediatr., 88: 273 (1976).

2. Bryan, M. H., Shennan, A., Griffin, E., and Angel, A.: Commentary: IntralipidIts rational use in parenteral nutrition of the newborn. Pediatrics, 58: 787 (1976).

3. Carlson, L. A. and Rossner, S.: A methodological study of intravenous fat tolerance test with Intralipid emulsion. Scand. J. Clin. Lab. Invest., 29: 270 (1972).

4. Cleary, T. G., Getz, S. L., and Pickering, L. K.: Effect of Intralipid on oxidative metabolic and functional activities of polymorphonuclear leukocytes (PMNL). Pediatr. Res., 15: 529 (Abstract) (1981).

5. Dhanireddy, R., Hamosh, M., Sivasubramanian, K. N., Chowdhry, P., Scanlon, J. W., and Hamosh, P.: Postheparin lipolytic activity and Intralipid clearance in very low-birth-weight infants. J. Pediatr., 98: 617 (1981).

6. English, D., Roloff, J. S., Lukens, J. N., Parker, P., Green, H. L., and Ghishan, F. K.: Intravenous lipid emulsions and human neutrophil function. J. Pediatr., 99: 913 (1981).

7. Fischer, G. W., Wilson, S. R., Hunter, K. W., and Maese, A. D.: Diminished bacterial defences with Intralipid. Lancet, 2: 819 (1980).

8. Forget, P. P., Fernandes, J., and Haverkamp Begemann P.: Utilization of fat emulsion during total parenteral nutrition in children. Acta Paediatr. Scand., 64: 377 (1975).

9. Franklin, F., Watkins, J. B., Heafitz, L., Clowes, A. W., and Breslow, J. L.: Serum lipids during total parenteral nutrition with Intralipid (TPN-IL). Pediatr Res., 10: 317 (Abstract) (1976).
10. Goldstein, A., Aronow, L., and Kalman, S. M.: The time course of drug action. In: Principles of drug action: The basis of pharmacology, 2nd ed. pp 301-356 (John Wiley and Sons, New York, 1974).

11. Greenblatt, D. J. and Koch-Weser, J.: Clinical pharmacokinetics. N. Engl. J Med., 293: 702 (1975)

12. Griffin, E., Breckenridge, W. C., Kuksis, A., Bryan, M. H., and Angel, A. Appearance and characterization of $\mathrm{Lp}-\mathrm{X}$ during continuous Intralipid infusions in the neonate. J. Clin. Invest., 64: 1703 (1979).

13. Griffin, E., Kuksis, A., Breckenridge, C., Jeejeebhoy, K., Bryan, M. H., and Angel, A.: Hypercholesterolemia and Lipoprotein-X $\left(L_{p}-\mathrm{X}\right)$ in total parenteral nutrition (TPN) with Intralipid. Clin. Res., 25: 311 (Abstract) (1977).

14. Gurson, C. T. and Saner, G.: Lipoprotein lipase activity in marasmic type of protein-calorie malnutrition. Arch. Dis. Child., 44: 765 (1969).

15. Gustafson, A., Kjellmer, I., Olegard, R., and Victorin, L.: Nutrition in low birthweight infants. I. Intravenous injection of fat emulsion. Acta Paediatr. Scand., 61 : 149 (1972)

16. Gustafson, A., Kjellmer, I., Olegard, R., and Victorin, L. H.: Nutrition in lowbirth-weight infants. II. Repeated intravenous injections of fat emulsion. Acta Paediatr. Scand., 63: 177 (1974).

17. Hallberg, D.: Studies on the elimination of exogenous lipids from the blood stream. Acta Physiol. Scand., 65: 254 (1965).

18. Kendall, M. G. and Stuart, A.: Standard errors. In: The advanced theory of statistics, Vol. 1, pp 243. (Charles Griffin \& Company Limited, London, 1977).

19. Levene, M. I., Wigglesworth, J. S., and Desai, R.: Pulmonary fat accumulation after Intralipid infusion in the preterm infant. Lancet, 2: 815 (1980).

20. Miyahara, T., Fujiwara, H., Yae, Y., Okano, H., Okochi, K., and Torisu, M Abnormal lipoprotein appearing in plasma of patients who received a ten percent soybean oil emulsion infusion. Surgery, 85: 566 (1979).

21. Periera, G. R., Fox, W. W., Stanley, C. A., Baker, L., and Schwartz, J. G.: Decreased oxygenation and hyperlipemia during intravenous fat emulsions in premature infants. Pediatrics, 66: 26 (1980)

22. Schreiner, R. L., Glick, M. R., Nordschow, C. D., and Gresham, E. L.: An evaluation of methods to monitor infants receiving intravenous lipids. J. Pediatr., 94: 197 (1979)

23. Shennan, A. T., Bryan, M. H., and Angel, A.: The effect of gestational age on Intralipid tolerance in newborn infants. J. Pediatr., 91: 134 (1977).

24. Sisson, T. R. C., Lung, C. J., Whalen, L. E., and Telek, A.: The blood volume in infants. J. Pediatr., 55: 163 (1959)

25. Smigura, F. C., Bryan, M. H., and Angel, A.: Post-heparin lipase activity in newborn infants. In: Hahn P., Ed., Isreals S., Ed.: The role of fat in intravenous feeding of the newborn. pp 129-139. (Pharmacia, Canada, Ltd., Dorval, Quebec, 1974).

26. Steel, R. G. D. and Torrie, J. H.: Analysis of variance one: The one way classification. In: Principles and procedures of statistics. p. 107 (McGraw-Hill Book Company, New York, 1960).

27. Steel, R. G. D. and Torrie, J. H.: Probability. In: Principles and procedures of statistics. p. 38 (McGraw-Hill Book Company, New York, 1960).

28. Usher, R. and McLean, F.: Intrauterine growth of live-born Caucasian infants at sea level: Standards obtained from measurements in 7 dimensions of infants born between 25 and 44 weeks gestation. J. Pediatr., 74: 901 (1969).

29. Wretland, A.: Complete Intravenous nutrition. Theoretical and experimental background. Nutr. Metabol., 14: 1 (1972).

30. Performed during her tenure as M.R.C. Fellow, and in partial fullfillment of M.D. degree by thesis, National University of Ireland.

31. Requests for reprints should be addressed to: Dr. M. H. Bryan, Mount Sina Hospital, 600 University Ave., Toronto, Ontario, Canada M5G IX5.

32. This work was supported from the H. J. Heinz Co. Ltd. of Canada and the Ontario Heart Foundation.

33. Received for publication May 11, 1982.

34. Accepted for publication September 27, 1982. 